\title{
El espacio teatral y su regulación jurídica en época romana: estructura y legislación ${ }^{1}$
}

\author{
Oliva Rodríguez Gutiérrez \\ Universidad Autónoma de Madrid.
}

\section{Resumen}

En los edificios teatrales de época romana se detectan algunas particularidades estructurales cuya naturaleza o, al menos, consolidación en estos espacios, puede buscarse en las normativas que sobre la distribución de puestos para los diferentes grupos sociales se emitieron ya desde época republicana, siendo posteriormente reformados o ratificados en muchos aspectos por la legislación imperial, comenzando por la Lex lulia Theatralis augustea, fiel reflejo de la ideología del nuevo sistema sociopolítico.

\begin{abstract}
The origin and consolidation of some features from the architectural structure of Roman theatres are close connected with the laws ordered about the organization and distribution on it of the different social groups of population. Good examples are known since Republican times, but the further reforms and ratification of them in Augustan Ages (Lex lulia Theatralis) are a clearer reflect of the new sociopolitical stablishment.
\end{abstract}

"Spectaret populum ludis attentius ipsis, ut sibi

praebentem nimio spectacula plura" ${ }^{2}$

\section{INTRODUCCIÓN}

Las disposiciones legales que fueron establecidas en torno a los edificios teatrales serán importantes para nosotros en la medida en la que permitan interpretar algunas de las peculiaridades y características de su estructura arquitectónica. Ya en los estudios más clásicos ${ }^{3}$ sobre los edificios teatrales grecorromanos se insistía en las significativas diferencias existentes entre los de una y otra tipología, sin que durante largo tiempo se cuestionara el porqué de dichas variantes, a pesar de defenderse, en muchos casos, una continuidad funcional entre ambos.

Todos y cada uno de los elementos estructurales que forman parte del teatro tendrán una

1. Este trabajo forma parte, en líneas generales, de nuestra tesis doctoral (Rodríguez Gutiérrez, 2001), defendida en diciembre de 2001 en el Departamento de Prehistoria y Arqueología de la Universidad Autónoma de Madrid y dirigida por Dr. D. Manuel Bendala Galán. El proyecto fue subvencionado por la Dirección General de Investigación de la Consejería de Educación y Cultura de la función determinada, nada será casual o accesorio. Especialmente en lo que se refiere a la cauea, muchas de sus características deben ser explicadas por el orden social vigente y como trasfondo, por las leyes que se encargaban de plasmarlo en su arquitectura. Sin duda alguna, el teatro fue el edificio que, dada la reducción de la vida asamblearia en época imperial, asumió importantes funciones como medio de reunión de los ciudadanos, siempre bajo la atenta mirada del emperador $\mathrm{o}$, en las provincias, de los magistrados municipales.

De hecho, el modelo de edificio que llega a las provincias procede del teatro construido por Pompeyo en el Campo de Marte el año 55 a.C. y de los posteriores de Marcelo y Balbo, augus-

Comunidad Autónoma de Madrid y el Fondo Social Europeo.

2. "Miraba con mayor interés a la muchedumbre que a los juegos, dado que aquélla ofrecía mucho mayor espectáculo", Horacio, Epistolas 2.1.197-198.

3. Como por ejemplo Bieber, 1961. 
teos, estructuralmente basados en el primero. Todos ellos reflejan en su morfología las pautas marcadas por dos textos legales: la Lex Roscia Theatralis del año 67 a.C. y sus posteriores enmiendas y ampliaciones en la Lex Iulia Theatralis ${ }^{4}$, que puede ser entendida como parte del gran programa de renovación social llevado a cabo por Augusto, enmarcado en los cura morum del 19 a.C. ${ }^{5}$. Aquí, de nuevo, se pone de relieve la herencia que el teatro imperial augusteo tomará de la tardorrepública ${ }^{6}$. Estas novedades se materializan también en importantes cambios estructurales frente al anterior teatro de influencia greco-helenística. La normativa legal fruto de ambas, Roscia y Iulia Theatralis, siguió vigente, al menos, hasta el siglo II d.C. A ellas es preciso añadir además la información que sobre este ordenamiento se extrae de legislaciones locales, de entre las que destaca la Lex Ursonensis ${ }^{7}$, del 44 a.C.; menos explícitas al respecto son la heraclea ${ }^{8}$ y la irnitana ${ }^{9}$.

A través de referencias en los propios textos dramáticos conservados, todo parece indicar que en tiempos de la comedia plautina los únicos asientos reservados en la cauea eran los destinados a las más altas dignidades ${ }^{10}$, mientras que el resto carecía de un orden claro y establecido ${ }^{11}$. Tito Livio ${ }^{12}$ narra que en el año 194 a.C. dos censores ordenaron conceder lugares especiales en los "espectáculos" para los miembros del ordo senatorius; por entonces, en el amplio espacio destinado a la plebs, tan sólo existiría distinción entre libres y esclavos.

La ley Roscia recuperó un antiguo texto abolido por Sila ${ }^{13}$ según el cual los miembros del

4. Suetonio, Aug., 40.1 y 44; Plinio, NH, 33, 8.

5. Rawson, 1991, 526.

6. Véase Cicerón, Philipicas, 2, 44 donde se alude a este ordenamiento tardorrepublicano de forma genérica.

7. D’Ors, 1953; 1988, Frei-Stolba; González, 1989.

8. Tabula Heraclea, lín. 133 y 138.

9. Lex Irnitana, 81.

10. Plauto, Captiui, 15 y ss.: "uso qui potestis ope uostra censerier accipite relicuom: alieno uti nil moror".

11. En Polemus, 10 y ss. Pociña, 1976, 437.

12. Auc. XXXIV, 44, 5 y 54.

13. Veleyo Patérculo, II, 32, 3; Cicerón Pro Mur, 40.

14. Suetonio, Diu. Iul., 39.2. Dada la variabilidad en las dimensiones de la cauea y en el número de filas de asientos, esta norma se adaptaría, en cada ciudad, a la población incluida en cada ordo y a la disponibilidad de espacio en el teatro.

15. Suetonio, Aug., 40, 1: "[...] como muchos caballeros, arruinados por las guerras civiles, no se atrevían a presenciar los juegos desde las catorce gradas por temor a la pena establecida por orden ecuestre podían ocupar las catorce primeras gradas situadas a continuación de las de los senadores ${ }^{14}$. Con Augusto, también los caballeros arruinados pudieron conservar estos puestos ${ }^{15}$, de los que les había privado la ley republicana. Si bien fue precisamente la inobservancia de ésta última, el hecho de ser usurpado el puesto de un senador en el teatro de Pozzuoli, lo que motivó la redacción de la ley augustea ${ }^{16}$, tampoco con ella se garantizó la disciplina. Son numerosas las alusiones a estas irregularidades en la literatura ${ }^{17}$, así como al establecimiento de elevadas multas en metálico para los infractores. Éstas eran de cinco mil sestercios ${ }^{18}$ según las leyes de Urso (44 a.C.), también para quienes tan sólo lo permitieran. Existía, incluso, además del dissignator, encargado de acomodar a los espectadores en sus lugares correspondientes ${ }^{19}$, la figura del apparitor, que velaba por los asientos de los senadores y magistrados ${ }^{20}$.

Según la tradición, el orden de los loci en la cauea en época augustea tuvo su primera manifestación en un senadoconsulto anterior al año 6 a.C. motivado por el episodio ya aludido de Puteoli. Sin embargo, en esta medida debe buscarse un mayor trasfondo en clave sociopolítica de acuerdo a la nueva ideología del régimen. Era preciso un estricto control social capaz de mantener la estabilidad y que dificultara la movilidad de individuos de unas clases a otras, siendo fundamental que cada uno asumiera y fuera consciente de su papel y lugar en la sociedad; como escribió E. Rawson ${ }^{21}$ : "As everyone realizes, Augustus' whole hierarchic vision of the society of the Roman Empire is involved, with his attemp to rebuild

la ley sobre el teatro, declaró que no estaban sujetos a ella aquéllos de ellos mismos o cuyos padres habían poseído alguna vez la fortuna ecuestre" (Para el texto de Svetorio seguimos, en todos los casos, la traducción de V. Picón, 2000).

16. Suetonio, Aug., 44, 1: [referido a la disposición en la cauea] Augusto la corrigió y la sometió a un reglamento, movido por la ofensa hecha a un senador que, en Pozzuoli, durante unos juegos concurridísimos, no había hallado a nadie que le hiciera sitio entre el numeroso concurso de espectadores”. Véase también Plinio, $N H, 33,8$.

17. Marcial, II, 29; III, 95, 10; V 8; 14; 23; 25; 41; VI 9; Suetonio, Cal. 26, 4; Dom. 8, 3; Horacio, Épodos, IV, 15-20.

18. Cantidad elevada considerando que el presupuesto total anual para juegos era de 14.000 sestercios.

19. Documentado en una inscripción procedente de Corduba: Vicent y Marcos, 1984-85, 65 y ss.; Luzón, 1998, 245.

20. Kolendo, 1981, 302.

21. 1991,509 . 
this society after the chaos of the triunviral period, when, to Roman eyes, discrimina ordinum had been scandalously overridden".

En la medida en la que la cauea teatral era un claro reflejo del orden social vigente, se convertía así, a modo de una ciudad dentro de la propia ciudad $^{22}$. Cada colectivo ocupaba su puesto, si bien hay que tener en cuenta que ni todos los grupos existentes en ella tenían un lugar establecido ni todos los que poseían éste se constituían en un ordo independiente; no existía una correspondencia unívoca. La sociedad romana se organiza en ordines ${ }^{23}$, grupos con diferentes funciones en la comunidad que, a su vez, poseían diferente gradus dignitatis ${ }^{24}$. Incluso, en el teatro, se hablaba de discrimina ordinum ${ }^{25}$, entendido como cada uno de los puestos a ocupar por los colectivos con status diferenciado.

Tras lo que parece haber sido una falta de definición previa, con la ley augustea se establece definitivamente el lugar destinado a las mujeres. Las vestales eran las únicas que contaban con un puesto privilegiado, en el tribunal opuesto al ocupado por el dator ludorum. A partir del año 24 d.C. a ellas se sumó Livia, manteniéndose desde entonces esta tradición para todas las emperatrices. El resto de las mujeres, aunque es muy probable que existiera una de distribución por rangos sociales ${ }^{26}$, ocupó los sectores más altos de la cauea, alejados de los hombres. Éste era también el área destinada a esclavos y no ciudadanos. Se observa así que los mejores puestos en el teatro eran, en último término, para quienes participaban de pleno derecho en la ciudadanía $y$, por consiguiente, en la medida en la que el sistema imperial lo permitía, también en la vida política; un nuevo dato que ratifica el valor del teatro como instrumento político, mucho más

22. Jiménez Salvador, 1993, 237.

23. Al respecto véase Alföldy, ${ }^{2} 1992$, especialmente 146 y ss y 198 y ss.

24. Cicerón, Pro Sestio, 120.

25. En Tácito, Ann., XIII, 54: "IIllic per otium] dum consessum caueae, discrimina ordinum, quis eques, ubi senatus percontantur, Plinio, NH, 33, 33: lege Iulia theatrali in quattuordecim ordinibus sedisset; postea gregatim insigne id adpeti coeptum, propter haec discrimina C. Princeps decuriam quintam adiecit". Rawson, 1991, 508; Kolendo, 1981, 302; González, 1998, 202-203.

26. Es difícil de precisar si las matronas, mujeres casadas y con hijos, podrían acompañar a sus maridos en sus puestos. De no ser así, y tener que situarse en la parte más alta de la cauea, habrían estado probablemente separadas de las de condición inferior, tales como prostitutas y meretrices. allá de mero lugar para el esparcimiento, la diversión y la celebración de espectáculos.

A partir de la jurisprudencia augustea los soldados, así como los veteranos, reciben un lugar diferenciado, dato que cobra sentido dado el acusado carácter militarista del nuevo régimen ${ }^{27}$. Es también a partir de entonces cuando se establece el puesto a ocupar por los extranjeros ${ }^{28}$, situado en la parte alta del graderío; en caso de tratarse de legados o altas dignidades podían ser revestidos de los ornamenta praetoria o consularia (decurionalia en las provincias), que les permitían acompañar a las elites en la proedria ${ }^{29}$. Es muy probable que en caso de peregrini de elevado rango, no interesara desde el punto de vista "diplomático" que se sintieran marginados. Es más, es posible que el teatro se convirtiera ante la población extranjera en una ostensible manifestación de poder y civilización, e una palabra, de "romanidad". De este modo, en las leyes de Urso se alude a los puestos reservados en los ludi scaenici a incolae, hospites y atventores ${ }^{30}$; no así en los circenses y gladiatorios, quedando de nuevo patente la mayor jerarquización presente en el teatro frente al resto de edificios de reunión y "espectáculos".

Los servi publici tuvieron reservado su lugar, al menos a partir de época de Augusto, dado su carácter de grupo privilegiado social y legalmente, señalado incluso con una vestimenta especial, el limus cinctus ${ }^{31}$. También los esclavos que se organizaban en collegia o los miembros de la familia caesaris pudieron acceder a posiciones más privilegiadas ${ }^{32}$. El resto asistía a las ceremonias en pie desde el sector más elevado y alejado de la cauea, no le estaban designados asientos. No obstante, tampoco siempre había asientos para toda la $p l e b s^{33}$, por lo que eran frecuentes las disputas por conseguir sitio sentados, situación que

27. Rawson, 1991, 527; Zanker, 1992, 222 y ss.

28. Suetonio, Aug. 44: "prohibió que en Roma ocuparan asientos de la orquesta los embajadores de los pueblos libres y aliados, pues se habia dado cuenta de que incluso se enviaba a algunos de la clase de los libertos".

29. Suetonio, Claud., 25.4. Del siguiente relato se desprende, no obstante, que, al menos hasta época de Claudio, no todas las embajadas extranjeras recibían el mismo tratamiento: partos y armenios se sentaban en la orchestra, vedada a los germanos.

31. Rawson, 1991, 515.

32. González, 1998, 618, (voz “spectator").

33. H.-N. Parker (1999, 166 sugiere) que era frecuente tener que llegar con mucha anterioridad para coger sitio; Plauto, Poen., 21; a su vez, en el circo, Suetonio, Calig, 26. 
trató de mejorar la Lex Iulia Theatralis al introducir mayor número de puestos reservados respondiendo a las más diversas variables sociales, tales como oficios o grupos de edad. De ello aparecen frecuentes alusiones no sólo en las fuentes - cuneus iuniorum $^{34}$-, sino también en la documentación epigráfica: iuniores y seniores ${ }^{35}$; es incluso posible que un graffito realizado sobre uno de los escalones de la proedria del teatro de Itálica ${ }^{36} \mathrm{y}$ donde consta ordo senei fueran también un testimonio de ello.

En las ciudades provinciales, tal y como se desarrolla en la Lex Ursonensis, los puestos privilegiados de la proedria estaban reservados a los decuriones, a los magistrados de la ciudad y a todos los que se les hubiera concedido tal privilegio, al menos con la mitad de los votos del ordo decurionum. Según consta en el capítulo 127 de dicho texto legal, puestos de excepción estaban también reservados en caso de la visita ocasional de magistrados y senadores llegados de Roma o cargos de la administración imperial. Asimismo, las máximas dignidades sacerdotales, como pontífices y augures, tenían su lugar entre los decuriones. En los puestos también se mantenía un numeroso grupo de antiguos magistrados que, a pesar de ello, conservaba sus privilegios ${ }^{37}$.

No obstante, no sólo la posición a ocupar fue regulada, sino también otros muchos aspectos como la vestimenta de los espectadores ${ }^{38}$. Los obligados ropajes blancos ${ }^{39}$, propios de determinados rituales y de la asistencia a los santuarios, señalan el carácter sacro del teatro en este momento. El resultado era la totalidad de la población dispuesta jerárquicamente, ataviada con las ropas y atributos característicos de su rango y posición social ${ }^{40}$. Al respecto de la vestimenta dirá H.-N. Parker "All male citizens who attended had to wear the toga. This is not just a mat-

34. Tácito, Ann. 2, 83: "Equester ordo cuneum Germanici appellauit qui iuniorum dicebatur [...]".

35. Citado por González, 1998, 618.

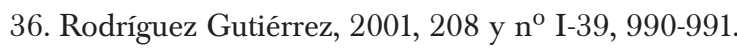

37. González, 1998, 620.

38. Al margen del enorme simbolismo y protocolo que suponemos en el atavío de los que participaban directamente como protagonistas y oficiantes en las ceremonias. Plauto, Amph, 68; Juvenal, 3, 171-179; Marcial, 5.23; Calpurnio Siculo I, 23-29.

39. Suetonio, Aug. 44: "prohibió que ningún espectador con toga oscura se sentara en la cauea media”.

40. A partir de César, por ejemplo, se permitió asistir al teatro con la corona de laurel, propia de aquéllos que habían obtenido honores militares (Casio Dión, 42, ter of dress code. Only with the toga could all the differences of status encoded in colored stripes and borders be seen. We must imagine the Roman theater audience divided into bright semicircles: in the front, the senators with the wide purple stripes on their tunics (latus clauus), the curule magistrates wearing the toga praetexta with its purple stripe. Next, the knights with the narrower purple stripes in their tunics (angustus clauus). Behind them, the plain white toga and tunic of the ordinary citizens and at the very back the poor wearing dark tunics of cheap wool ${ }^{41}$ ".

Este ordenamiento no fue un mero capricho de Augusto, sino un claro reflejo de la política y de la ideología del régimen: el rechazo a determinados grupos sociales no ciudadanos tales como las mujeres, los esclavos o los extranjeros; la política natalicia, en la que se fomentaban las familias numerosas y que llevaba a sancionar, entre otros, a las viudas que tardaban en contraer nuevas nupcias o a los solteros; a éstos últimos se les prohibió incluso la entrada al teatro. Como vemos, esta legislación no solamente incluía honores y privilegios sino también discriminaciones. La cuestión que necesita aún de mayor precisión, ya que las referencias en las fuentes son escasas y resultan en muchas ocasiones parciales, es si esta disposición habría sido constante para todo tipo de actos o si podía ser variada respondiendo a diferentes ceremonias y eventos.

Desde el punto de vista de la estructura arquitectónica del edificio, este nuevo orden tiene claras evidencias en los siguientes elementos ${ }^{42}$ :

1) La marcada división horizontal en tres maeniana con praecinctiones claramente diferenciadas incluso con barreras o baltei entre ellas ${ }^{43}$.

2) La construcción exenta de la cauea por medio de substrucciones generaba una red

19, 3; 43, 43, 1; Suetonio, Julio, 76; Livio, AUC, 10, 47, Plinio NH, 16.13).

41. Parker, 1999, 166; veáse también en el mismo volumen Edmonson, 1999, 84-86; Jones, 1999, passim.

42. De otros posibles rasgos de distinción, especialmente entre los miembros de la plebs o de los grupos más desfavorecidos que se concentraban en la summa cauea, no ha quedado evidencia en el registro arqueológico ya que incluso ni siquiera habrían existido medios físicos para ello, sino tan sólo convenciones conocidas por todos que, en caso de ignorarse recibían la penalización correspondiente, tal y como se recoge en las leyes de Urso.

43. En el teatro griego esta distinción es prácticamente inexistente (Rawson, 1991, 510). 
de galerías concéntricas y radiales internas que comunicaban con los diferentes puntos del graderío, permitiendo así dirigir desde el acceso, de forma selectiva, a cada uno de los espectadores a su puesto correspondiente.

3) Se produce así una jerarquización en el ingreso al edificio que, en su sector inferior se configura por medio del cierre del edificio con la transformación de los parodoi en pasillos cubiertos. A través de los itinera se accede a la orchestra-proedria y a los tribunalia.

4) La summa cauea fue susceptible de presentar una diferenciación interna por medio de una ancha praecinctio a la que se abrían además los uomitoria o galerías de acceso desde el exterior.

5) Los tribunalia: estos espacios situados sobre los itinera, abiertos a la orchestra y la scaena, eran los ocupados por el dator ludorum, magistrado que ofrecía los juegos.

6) En la orchestra se distingue la proedria que, en muchos teatros, se encuentra separada del resto de las gradas por un alto balteus marmóreo. En ella se situaban los sitiales (subsellia) de las elites municipales así como de sus invitados ocasionales. La aristocracia municipal podía incluso llegar a ocupar estos asientos en propiedad ${ }^{44} \mathrm{y}$ a perpetuidad, de ahí que en muchas ocasiones los individualizara físicamente.

7) También algunos sectores del graderío, pudieron recibir un acabado marmóreo como signo de distinción de los que allí se acomodaban.

8) Distribuidos en diferentes puntos de la cauea de un buen número de teatros se han identificado epígrafes y símbolos haciendo alusión a los individuos, familias, ordines o collegia a los que estaban destinados. De ello existen interesantes ejemplos en el anfiteatro flavio, donde se conservan evidencias epigráficas del lugar y la extensión que podí-

44. Kolb, 1999, 104, para el caso de Termessos.

45. CIL VI, 32098 a; Rawson, 1991, 512.

46. Fuchs, 1987, 165-166; Piernavieja, 1977.

47. Para las características de cada una de ellas y su evolución, especialmente en lo que se refiere al edificio escénico, véase Courtois, 1989, 51-53 (fase helenística); 70-75 (silana); 121-125 (augustea), 223-226 (reforma del 62 d.C.).

48 No obstante, que también se incluirá en algunas ceremonias parece extraerse del protocolo de los ludi sae- an y debían ocupar determinados grupos como los praetextati y sus paedagogi, probablemente también ajustándose a la antigua ley augustea ${ }^{45}$. Una serie más próxima pero no menos interesante ha sido documentada en el también anfiteatro de Itálica ${ }^{46}$.

Un buen ejemplo de algunas de las transformaciones motivadas por el nuevo y estricto ordenamiento social augusteo se encuentra en el teatro mayor de Pompeya. Al margen de la evolución sufrida a partir de la primera estructura helenística a fin de adaptarse a las nuevas necesidades del teatro romano ${ }^{47}$, es fundamental la acción llevada a cabo por los Holconii en la cauea en torno al cambio de Era. En la línea de ese nuevo teatro augusteo, se añade un cuerpo a la summa cauea para integrar a grupos sociales que, no obstante, quedan aislados del resto de espectadores por medio de una barrera arquitectónica y de un acceso independiente. La unión de cauea y escena permite, además, la inclusión de los tribunalia a los que se accede desde los itinera. La orchestra, ahora sin participación en las representaciones -sensu stricto ${ }^{48}$, , continúa siendo un importante foco de atención del respetable, acogiendo a las elites y, muy probablemente, muchos de los elementos de la simbología imperial.

Se documentan además otras medidas más excepcionales como la instalación de sillas honoríficas. En la mayor parte de los casos conocidos se incluyen en homenajes póstumos ${ }^{49}$, pero tampoco faltaron formando parte de honores en vida, como en el caso del pompeyano $\mathrm{M}$. Holconio Rufo ${ }^{50}$. En el teatro italicense ha sido documentada una estructura de opus testaceum apoyada sobre el balteus, en la proedria. Ésta pudo tener como objeto no solamente ser el soporte de algún tipo de elemento honorífico, sino, más aún, impedir que los antiguos asientos en la orchestra destinados a determinados ciudadanos destacados, ya desaparecidos, fueran de nuevo ocupados, dejando de este modo perpetua memoria.

culares tanto augusteos (17 a.C.) como severianos (204 d.C.) en los que se alude a Graeci thymelici (Aug. 160161; Pighi, 1964-1985, 2117).

49. Destacando los casos de Germánico (Tácito, 2, 83, 1); la emperatriz Faustina, de la que, con motivo de la asistencia de Marco Aurelio al teatro, se colocaba una estatua de oro en un asiento destinado a tal efecto (Casio Dión, 72, 31, 4); o el ciudadano de Herculano M. Nonnio Balbo (AE, 1947, 53; 1976, 144; CIL X 1427).

50. CIL X 833, 834, 835 . 


\section{Anexo}

\section{Suetonio, Augusto, 44.}

"La manera de asistir a los espectáculos no podía ser más desordenada y negligente; Augusto la corrigió y la sometió a un reglamento, incitado por una afrenta inferida en Pozzuoli a un senador a quien, con ocasión de unos juegos muy concurridos, no se hizo sitio entre los numerosos espectadores que se hallaban sentados. Se promulgó un decreto del Senado por el que debía reservarse a los senadores la primera fila de asientos cada vez que se diera en cualquier parte un espectáculo público, y prohibió que en Roma ocuparan asientos de la orquesta los embajadores de los pueblos libres y aliados, pues se habia dado cuenta de que incluso se enviaba a algunos de la clase de los libertos. Separó a los soldados del pueblo. Asignó a los plebeyos casados unas gradas especiales, así como su propia sección a los que todavía vestían la praetexta y la contigua a sus preceptores, y prohibió ocupar las gradas centrales a toda persona vestida de oscuro. En cuanto a las mujeres, no les permitió presenciar ni siquiera los combates de gladiadores, que desde hacía tiempo era habitual que presenciaran mezcladas con el público, sino desde las gradas más altas y ellas solas. Dio a las vírgenes vestales un asiento aparte en el teatro, frente al estrado del pretor ${ }^{51}$ ".

\section{Bibliografía}

ABASCAL, J.M. y EsPinOSA, U. (1989): La ciudad hispanorromana: privilegio y poder, Logroño.

AlfÖLDY, G. ( $\left.{ }^{2} 1992\right)$ : Historia social de Roma, Madrid.

Bieber, M. (1961): The History of the Greek and Roman Theater, Princeton, New Jersey.

Courtois, C. (1989): Le bâtiment de scène des théâtres d'Italie et de Sicile. Etude chronologique et typologique, Providence - Louvain-la-Neuve.

D’Ors, A. (1953): Epigrafía jurídica de la España romana, Madrid.

Edmonson, J.C. (1999): " The cultural Politics of Public Spectacle in Rome and the Greek East, 167-166 BCE”, en Bergmann, B. y Kondoleon, C. (eds.) The Art of Ancient Spectacle, New Haven-London, 77-95.

FuCHS, M. (1987): Untersuchungen zur Ausstaltung römischer Theater in Italien und den Westprovinzen des Imperium Romanum, Maguncia.

GonZÁLEZ, J (ed.) (1989): Estudios sobre Urso, Colonia Iulia Genetiva, Sevilla.

GonZÁlez VÁzQuez, C. (1998): Diccionario del teatro lati- no. Léxico, dramaturgia, escenografía. Tesis doctoral inédita, Universidad Autónoma de Madrid.

Jiménez SALVAdor, J.L. (1993): “Teatro y desarrollo monumental urbano en Hispania", Teatros romanos de Hispania, Cuadernos de Arquitectura romana, 2, Murcia, 225-238.

Jones en Bergmann, B. y Kondoleon, C. (eds.) The Art of Ancient Spectacle, New Haven-London, 247-257.

Kolb, F. (1999): "Die Sitzordnung von Volksversammlung und Theaterpublikum im kaiserzeitlichen Ephesos", en Friesinger, H. y Krinzinger, F. (Hrsg.): 100 Jahre Österreichische Forschungen in Ephesos, Akten des Symposions, Viena 1995, Viena, 101-105.

Kolendo, J. (1981): "La répartition des places aux spectacles et la stratification sociale dans l'Empire Romain. A propos des inscriptions sur les gradins des amphitheatres et théâtres", Ktema, 6, 301-315.

LuZÓN NoguÉ, J.M. (1998): "Espectáculos públicos en las ciudades hispanorromanas”, Hispania. El legado de Roma, 239-248.

PARker, H.-N. (1999): "The Observed of All Observers: Spectacle, Applause and Cultural Poetics in the Roman Theater Audience", en Bergmann, B. Y Kondoleon, C. (eds.) The Art of Ancient Spectacle, New Haven-London, 163-179.

Picón, V. (ed.) (2000): Suetonio, La vida de los doce césares, Madrid.

Pighi, G.B. (1964-1985): voz "Ludi Saeculares", en Dizionario Epigrafico di Antichità romane, vol. IV, parte III, 2106-2125.

Pociña Pérez, A. (1976): "Los espectadores, la Lex Roscia Theatralis y la organización de la cavea en los teatros romanos", Zephyrus, XVI-XVII, 435-442

Rawson, E. (1991): "Discrimina Ordinum: The Lex Iulia Theatralis", en Roman Culture and Society, Oxford, 508-545

Rodríguez GuTIÉRREZ, O. (2001): El teatro romano de Itálica. Estudio arqueoarquitectónico, Tesis doctoral inédita, Univ. Autónoma de Madrid.

Vicent, A. M a y Marcos, A. (1984-85): "Inscripción funeraria de un dissignator", Corduba Arqueológica, 15, 65-66.

Zanker, P. (1992): Augusto y el poder de las imágenes, Madrid.

51. A partir de la traducción de V. Picón (2000). 